\title{
Screening for anti-adipogenic, pro-lipolytic and thermogenic plant extracts by models associating intestinal epithelial cells with human adipose cells
}

\author{
Damien Guillemet ${ }^{1}\left[\right.$ C Chloé Belles ${ }^{2} \cdot$ Aurélie Gomes $^{3} \cdot$ Vincent Azalbert $^{4} \cdot$ Mathilde André $^{2} \cdot$ Nourdine Faresse $^{2}$. \\ Rémy Burcelin ${ }^{4} \cdot$ Jean-Michel Lagarde ${ }^{3} \cdot$ Danièle Lacasa $^{2} \cdot$ Mayoura Kéophiphath $^{2}$ (1)
}

Received: 26 October 2020 / Accepted: 21 December 2021 / Published online: 29 January 2022

(c) The Author(s) 2022

\begin{abstract}
Purpose Excessive fat mass accumulation in obesity leads to diverse metabolic disorders, increased risks of cardiovascular diseases and in some cases, mortality. The aim of this study was to screen the actions of botanical extracts intended for oral use on human adipose tissue, using an in vitro screening model combining human intestinal cells with human adipose cells. This was to find the most effective extracts on lipid accumulation, UCP1 expression and ATP production in pre-adipocytes and on adipocyte lipolysis.

Methods In this study, 25 individual plant extracts were screened for their effects on human adipose cells. Consequently, an original in vitro model was set up using the Caco-2 cell line, to mimic the intestinal passage of the extracts and then exposing human adipose cells to them. The biological actions of extracts were thus characterized, and compared with a coffee extract standard. The most effective extracts, and their combinations, were retained for their actions on lipid accumulation, the expression of the thermogenic effector UCP1 and ATP production in pre-adipocytes as well as on lipolysis activity of mature adipocytes.

Results The biphasic culture system combining human Caco-2 cells with human adipose cells was verified as functional using the green coffee extract standard. Out of the 25 plant extracts studied, only 7 and their combinations were retained due to their potent effects on adipose cells biology. The data showed that compared to the coffee extract standard, Immortelle, Catechu, Carrot and Rose hip extracts were the most effective in reducing lipid accumulation and increased UCP1 expression in human pre-adipocytes.

Conclusion This study reveals the potential inhibitory effects on lipid accumulation and thermogenic activity of Immortelle, Catechu, Carrot and Rose hip extracts, and for the first time synergies in their combinations, using an in vitro model mimicking as closely as possible, human intestinal passage linked to adipose cells. These findings need to be confirmed by in vivo trials.
\end{abstract}

Keywords Plant extracts · Adipose cells · Caco-2 $\cdot$ Lipid accumulation · UCP1 · Energy metabolism · Lipolysis

Damien Guillemet and Chloé Belles have contributed equally to this work.

Damien Guillemet

d.guillemet@nexira.com

$\triangle$ Mayoura Kéophiphath

mayoura.keophiphath@diva-expertise.com

1 Nexira, 129 chemin de Croisset, 76000 Rouen, France

2 Centre Pierre Potier, D.I.V.A. Expertise, 1 place Pierre

Potier, 31100 Toulouse, France
3 Centre Pierre Potier, Imactiv 3D, 1 place Pierre Potier, 31100 Toulouse, France

4 Institute of Cardiovascular and Metabolic Diseases, 1 avenue du Professeur Jean Poulhès, 31432 Toulouse, France 


\section{Introduction}

According to the World Health Organization, the prevalence of overweight and obesity in 2016, was 39\% of adults [1]. The burden of morbidity from obesity is strongly linked to cardiovascular and chronic inflammatory diseases [2]. Excessive accumulation of adipose tissue (AT) triggers systemic low-grade inflammatory pathways through local immune cells [2-5], hence, representing a major target for research in obesity and associated metabolic diseases [6]. The increase of AT mass is due to hypertrophy (increase in adipocyte size, i.e., lipogenesis) and hyperplasia [7, 8]. Hypertrophic expansion of mature adipose cells has been shown to promote insulin resistance and other obesity-associated metabolic complications and to be a consequence of inability to recruit new adipose progenitors. Hyperplasia (or adipogenesis) is a fundamental process of increased adipocyte number, and thus of tissue growth, by maturation of pre-adipocytes from an established pool during childhood and would be more protective than deleterious regarding obesity-associated metabolic disorders [9].

AT constitutes different adipocyte types, each with specific functions. While white adipocytes are specifically dedicated to the control of triglycerides and fatty acid storage and fluxes, brown adipocytes have a thermogenic activity which consists of the production of body heat through increased adipocyte metabolism [10]. Interestingly, beige adipocytes share common activities with both white and brown adipocytes. Hence, in the context of early-stage comorbid obesity, AT modulation and specifically, the stimulation of beiging and thermogenesis through UCP1 expression, has now become a target of choice [11-13] and needs to be studied to elucidate preventive and therapeutic strategies, with the additional advantage of not having lipids released into the blood stream.

Accessibility of any targeted tissue to orally administered products, requires the consideration of the different steps involved. Pharmacokinetic evaluation is defined by the combination of the processes of liberation (compounds released in the gut lumen), absorption (plasmatic or blood uptake kinetics), metabolization (chemical conversion by host cells) and excretion. In addition, other processes are also implicated in the bioavailability of products taken orally, such as their distribution to specific tissues, pharmacodynamics (drug and other compound interactions) as well as the more recently studied, metabolization by microbiota.

However, to be able to investigate in detail these processes in vitro, models which mimic as closely as possible these steps, have been or need to be set up. Regarding the simulation of the gastrointestinal tract, models dedicated to the investigation of colic metabolism, models such as Shime ${ }^{\circledR}[14]$ and that for studying digestion in the upper intestinal tract (gastric and the small intestine), Tim ${ }^{\circledR}$ [15], have already been set up and used. Though, these models have the limitation of compound absorption and metabolization by the intestinal cells and are moreover, not really adapted to high-throughput screening.

Then again, other in vitro models focus mainly on epithelial cell-like cultures, especially in contiguous monolayer systems to simulate the intestinal mucosal barrier. In addition, Caco- 2 cells differentiated into a monolayer have an enterocyte-like phenotype and are the primary cellular model used to mimic the human intestinal epithelium, with the apical side facing the intestinal lumen and the basolateral side facing the connective tissue [14]. Caco-2 cells also express, efflux proteins, and enzymes capable of metabolizing molecules to ensure the chemical conversion of test substances. That is why Caco- 2 cells have widely been used to quantify trans-epithelial transport, using radio-tracers or tracers labeled with stable isotopes, which can thereby be detected using LC or GC-MS [15].

In previous studies, in vitro models were developed to determine the relationship between Caco- 2 cells and adipose biology in co-culture systems. Ishihara R. et al. showed that Caco-2-derived secretions modulate the secretion of the two major adipokines, namely Leptin and Adiponectin, by immortalized rodent-derived adipocyte cells [16]. The bi-directional cellular relationship has also been demonstrated, by $\mathrm{Wu}$ and colleagues, showing that the inflammatory state of cultured adipocytes influenced the tightness of Caco-2 cell monolayers [17]. More recently, an in vitro multi-culture model, allowing the measurement of intestinal absorption using adipocytes has been described. In this model, immortalized murine pre-adipocytes were used as sensors of intestinal lipid absorption from a reconstituted intestinal barrier using Caco-2 and HT29-MTX cells [18]. Based on these different observations and aside from some limitations, the development of an in vitro system combining Caco-2 cells and human primary adipose cells represents an interesting strategy to mimic the intestinal passage of oral products and their potent effects on targeted human adipose tissue.

Furthermore, nutraceuticals and botanicals have been demonstrated, in separate studies, to have significant effects in adipocyte and fat mass modulation. However, most of them were performed on animal in vitro or in vivo models which do not allow a direct comparison of efficacy between them and further demonstrate their limitations, hence weakening their physiological relevance to humans. Indeed, differences between human and animal adipose tissue metabolism are well documented [19, 20]. Moreover, another important bias is the lack of understanding of the mechanisms involved in the local bioavailability substances, as documented by the limited in vivo activity of polyphenols, when compared to in vitro studies 


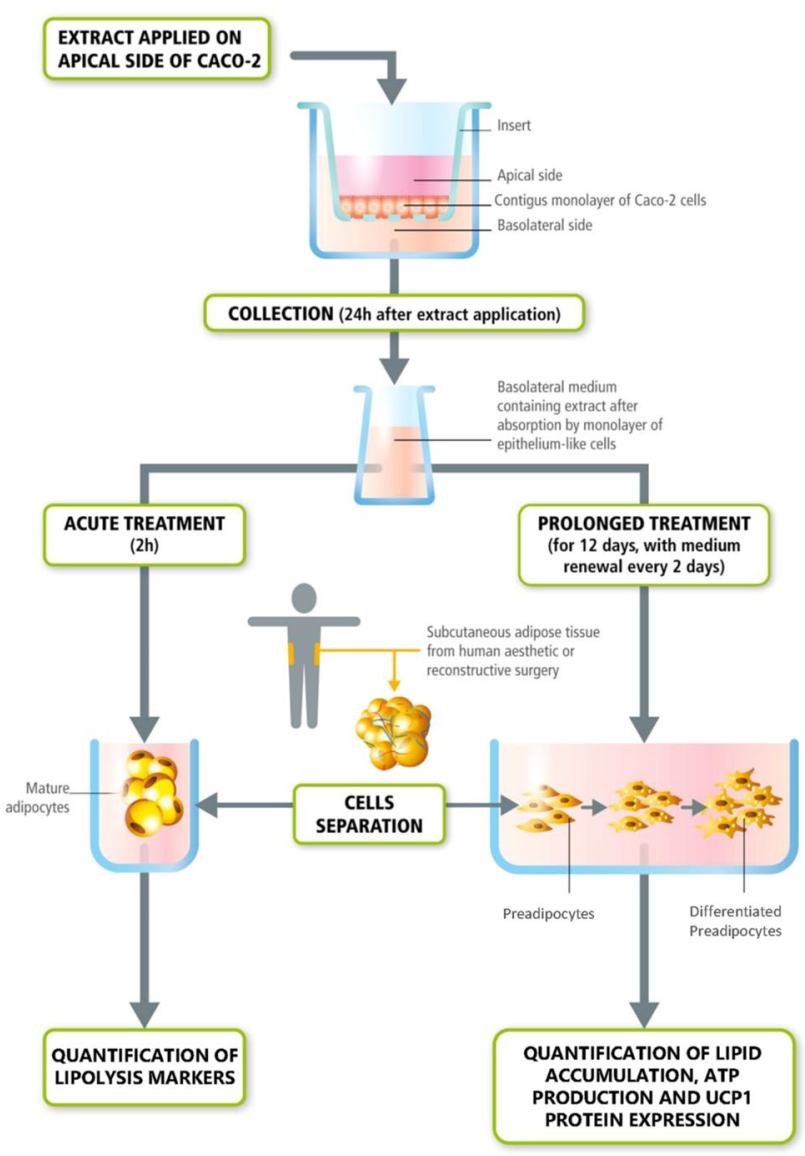

Fig. 1 Schematic representation of the in vitro bi-phasic culture system. The first stage consists of aqueous plant extract application on Caco-2 cell monolayer inserts, then the basolateral medium (BM) is recovered after $24 \mathrm{~h}$ to mimic in vivo intestinal passage. The second stage consists of collected BM application on human adipose cells in 2 different models: acute treatment $(2 \mathrm{~h})$ of mature adipocyte (for lipolysis evaluation throughout NEFA and glycerol release) and prolonged treatment (10-12 days) of pre-adipocytes in pro-adipogenic condition (for lipid accumulation, ATP production and UCP1 protein expression)

$[21,22]$. Indeed, some polyphenols cannot be absorbed in their native form and require hydrolysis and/or (de-) conjugation to facilitate their penetration through apical transporters. As a result, epithelial cells can metabolize polyphenols back into a glucuronidated form, which can then, be excreted by basolateral transporters [23, 24].

To this end, in this study, we set up an in vitro system comprising a bi-phasic culture, combining the Caco- 2 cell line monolayer, with primary human adipose cells. Hence, several botanical extracts and their combinations, as compared to coffee extract standard, were used after traversing the Caco-2 monolayer, in characterizing their effects on human adipose cells (Fig. 1).

\section{Materials and methods}

\section{Botanical extract preparation and posology}

All edible botanical ingredients were extracted, dried and made into the powder form prior to use in the trials. Table 1 describes the botanical source, the Latin name, the plant part used, and the process of extraction applied for each selected botanical extract. For each of them, a concentration factor, relative to the botanical reference, was calculated based on the yield of extraction and the hypothetical posology correlation. This initial concentration factor was used for application in cytotoxicity trials on Caco- 2 cells. Depending on the cytotoxicity score obtained, final concentrations were defined and used for the conduction of the entire in vitro trial (supplemental results).

\section{Verification of the use of green coffee as a standard plant extract}

An extract of green coffee containing caffeine and chlorogenic acid, was used as the reference product, as its properties of modulating adipocyte metabolism, are well documented [25-27].

After verifying the absence of cytotoxic effects (Suppl. Fig.S1), the impact of this extract on pre-adipocyte differentiation was analyzed by assessing lipid accumulation in human pre-adipocytes.

The lipolytic activity of adipocytes was evaluated by measuring the extracellular release of glycerol and nonesterified fatty acids (NEFA) after stimulation with the lipolytic agents Forskolin $(1 \mu \mathrm{m})$ and Isoproterenol $(0.1 \mu \mathrm{m})$, or with the basolateral medium from Caco-2 cells in contact or not with green coffee extract. The effect of green coffee on the mitochondrial activity of pre-adipocytes was also carried out to determine the relevance of using the combined Caco-2 with adipose cells, by confirming the caffeine effect of green coffee as a standard, so that other plant extracts could then be tested. As UCP1 is strongly expressed in differentiated tissues as brown/beige adipose tissue, it was quantified in the differentiated pre-adipocytes. The effect of green coffee extract on the UCP1 levels on pre-adipocytes was determined. Finally, mitochondrial ATP synthase activity was also analyzed by quantifying the production of ATP. The condition $\mathbf{B M}+$ green coffee extract corresponds to basolateral media of caco- 2 cells exposed to green coffee extract and is considered as the reference product condition to verify the model. 
Table 1 Botanical source, plant part, process of extraction and relative initial/final concentrations tested for cytotoxicity on Caco-2 cells

\begin{tabular}{|c|c|c|c|c|c|c|}
\hline Code & Latin name & Vernacular name & Plant part & $\begin{array}{l}\text { Extraction (Raw } \\
\text { material:Solvent) }\end{array}$ & $\begin{array}{l}\text { Initial con- } \\
\text { centration } \\
(\mathrm{g} / \mathrm{L})\end{array}$ & $\begin{array}{l}\text { Final con- } \\
\text { centration } \\
(\mathrm{g} / \mathrm{L})\end{array}$ \\
\hline & Coffea arabica & Green coffee & Seeds (crushed) & $\mathrm{S} / \mathrm{L}$ water extraction-1:10 & 0.72 & 0.72 \\
\hline A & Morus alba & White mulberry & Leaves (dried) & S/L water extraction-1:15 & 0.72 & 0.72 \\
\hline B & Vigna angularis & Red adzuki & Seeds (whole) & $\mathrm{S} / \mathrm{L}$ water extraction- $1: 10$ & 0.36 & 0.36 \\
\hline $\mathrm{C}$ & Balanites aegyptiaca & Desert date & $\begin{array}{l}\text { Cake (residue after seed } \\
\text { pressing) }\end{array}$ & $\mathrm{S} / \mathrm{L}$ water extraction- $1: 10$ & 1.44 & 0.18 \\
\hline $\mathrm{D}$ & Magnolia officinalis & Magnolia & Bark (dried. Crushed) & $\mathrm{S} / \mathrm{L}$ water extraction-1:20 & 0.72 & 0.36 \\
\hline $\mathrm{E}$ & Olea europea & Olive & $\begin{array}{l}\text { Fruits (olive mill waste- } \\
\text { water) }\end{array}$ & absorbent resin purification & 0.72 & 0.36 \\
\hline $\mathrm{F}$ & Aframomum melegueta & Grains of paradise & Seeds (crushed) & $\mathrm{S} / \mathrm{L}$ water extraction- $1: 10$ & 0.18 & 0.18 \\
\hline G & Cinnamomum aromaticum & Chinese cinnamon & Bark (crushed) & S/L water extraction- $1: 10$ & 0.36 & 0.072 \\
\hline $\mathrm{H}$ & Nelumbo nucifera & Lotus & Flowers (dried) & $\mathrm{S} / \mathrm{L}$ water extraction-1:20 & 0.54 & 0.54 \\
\hline $\mathrm{J}$ & Mangifera indica & Mango & Fruit peel (dried crushed) & $\mathrm{S} / \mathrm{L}$ water extraction- $1: 10$ & 0.54 & 0.18 \\
\hline $\mathrm{L}$ & Acacia catechu & Catechu & Bark (dried. Crushed) & $\begin{array}{l}\text { S/L water extraction }(0.1 \\
\mathrm{NaOH})-1: 10\end{array}$ & 1.44 & 0.72 \\
\hline M & Arctium lappa & Greater burdock & Seeds (whole) & $\mathrm{S} / \mathrm{L}$ water extraction- $1: 10$ & 0.54 & 0.18 \\
\hline $\mathrm{N}$ & Commiphora mukul & Guggul & $\begin{array}{l}\text { Tree exudate (dried. } \\
\text { Crushed) }\end{array}$ & $\mathrm{S} / \mathrm{L}$ water extraction- $1: 10$ & 0.54 & 0.18 \\
\hline $\mathrm{O}$ & Daucus carota & Carrot & Seeds (whole) & $\mathrm{S} / \mathrm{L}$ water extraction- $1: 10$ & 0.36 & 0.18 \\
\hline $\mathrm{P}$ & Perilla frutescens & Shiso & Seeds (whole) & $\mathrm{S} / \mathrm{L}$ water extraction- $1: 10$ & 0.18 & 0.036 \\
\hline Q & Perilla frutescens & Shiso & Leaves (dried. Crushed) & S/L water extraction- $1: 10$ & 0.54 & 0.18 \\
\hline $\mathrm{R}$ & Cinnamomum verum & Ceylon cinnamon & Leaves (dried. Crushed) & $\mathrm{S} / \mathrm{L}$ water extraction- $1: 10$ & 0.18 & 0.036 \\
\hline$S$ & Alpinia galangal & Greater galangal & Rhizome (dried. Crushed) & S/L water extraction- $1: 10$ & 0.54 & 0.36 \\
\hline $\mathrm{T}$ & Salacia reticulata & Salacia & Roots (dried. Crushed) & $\mathrm{S} / \mathrm{L}$ water extraction-1:11 & 0.54 & 0.36 \\
\hline $\mathrm{U}$ & Syzygium aromaticum & Clove & Flower buds & $\mathrm{S} / \mathrm{L}$ water extraction- $1: 10$ & 0.18 & 0.072 \\
\hline V & Rosa canina & Rose Hip & Fruits (dried. Crushed) & $\mathrm{S} / \mathrm{L}$ water extraction- $1: 10$ & 0.72 & 0.72 \\
\hline W & Syzygium cumini & Jambolan & Seeds (crushed) & $\mathrm{S} / \mathrm{L}$ water extraction- $1: 10$ & 0.36 & 0.36 \\
\hline$X$ & Fragaria $\mathrm{x}$ ananassa & Strawberry & Seeds (achens) & $\begin{array}{l}\text { S/L hydro-alcoholic }(50 / 50) \\
\quad \text { extraction- } 1: 10\end{array}$ & 0.18 & 0.18 \\
\hline $\mathrm{Y}$ & Urtica dioica & Nettle & Leaves (dried) & $\mathrm{S} / \mathrm{L}$ water extraction & 0.18 & 0.18 \\
\hline $\mathrm{Z}$ & Jasminum officinalis & Jasmine (white) & Flowers (whole) & $\mathrm{S} / \mathrm{L}$ water extraction- $1: 20$ & 0.72 & 0.72 \\
\hline $\mathrm{Aa}$ & Helichrysum italicum & Immortelle & $\begin{array}{l}\text { Aerial parts (dried. } \\
\text { Crushed) }\end{array}$ & Water extraction-1:15 & 0.54 & 0.54 \\
\hline
\end{tabular}

\section{Caco- 2 culture and differentiation}

Caco- 2 cells were seeded at a density of $25 \times 10^{4}$ cells on transwells $(0.4 \mu \mathrm{m}$ pore-size polycarbonate membranes) placed in 6-well plates at $37{ }^{\circ} \mathrm{C}$ and $5 \% \mathrm{CO}_{2}$. Apical chambers were filled with $1.5 \mathrm{ml}$ of complete medium (DMEM supplemented with $20 \%$ heat inactivated Fetal Bovine Serum (FBS), $1 \%$ non-essential amino acids and $1 \%$ antibiotics) and the basolateral chamber with $2.5 \mathrm{ml}$ of the same medium. Culture media were changed every day for 21 days to obtain confluent differentiated cell monolayers [14, 28]. Then, the differentiated Caco- 2 cells on the apical side were treated with predefined concentrations of the plant extracts (Table 1). After a 24-h incubation period, basolateral media (BM) were collected and frozen at $-80{ }^{\circ} \mathrm{C}$ for subsequent experiments on human adipose cells. The condition
BM-extract corresponds to basolateral media of caco- 2 cells not exposed to botanical extracts and is considered as the control condition to compare the effects of botanical extracts with.

\section{Plant extract cytotoxicity on Caco-2}

Caco-2 cells were seeded in 96-well plates and confluent differentiated cell monolayers were treated with predefined concentrations of the extracts for $48 \mathrm{~h}$. Culture media were collected, and the cytotoxic effect of the extracts was determined by cytotoxic scoring including the activity of the lactate dehydrogenase (LDH, CytoTox-OneTM Fluorescent Assay, G7891, Promega) released, as well as, cell morphology and cell mortality rate after trypan blue staining (15,250,061, Gibco). These scores ranged from 1 (not 
cytotoxic) to 5 (very highly toxic) and were defined by comparing with the untreated control Caco- 2 cells. A botanical extract was considered as cytotoxic if its three scores were superior to or equal to 3 (Suppl. Fig. S2).

\section{Determination of the cytotoxic concentrations of plant extracts}

The non-cytotoxic concentrations of the extracts on Caco-2 cells were determined using cytotoxic scoring, based on lactate dehydrogenase (LDH) release, the morphological aspect of the cells and the rate of cell mortality (Suppl. Fig.S2). The non-cytotoxic concentration of each extract (cytotoxic scoring $<3$ ) for Caco- 2 cells, was then used for the $24 \mathrm{~h}$-treatment of differentiated Caco- 2 cells. Then, to determine the dilution ratio of basolateral media from Caco- 2 culture to apply to adipose cell culture media, 3 dilutions: 1/4, 1/8 and $1 / 10$, were tested for their cytotoxicity on pre-adipocytes, as measured by LDH release and formazan production.

\section{Cytotoxic effects of the basolateral medium (BM) from Caco- 2 cells treated with plant extracts on human pre-adipocytes}

Pre-adipocytes were seeded in 96-well plates and were cultured in DMEM-1\% FBS containing the basolateral media (BM) from Caco-2 cells treated with the extracts for $24 \mathrm{~h}$, and the media were changed every 2 days throughout the culture period of 6 to 7 days. At the end of the culture period, cytotoxicity was assessed by the measurement of the lactate dehydrogenase (LDH) released in the pre-adipocytes' culture medium (using CytoTox-OneTM Fluorescent Assay, G7891, Promega), and the number of viable cells was measured using the MTS proliferation assay (CellTiter $96^{\circledR}$ AQueous One Solution Cell Proliferation Assay, G3580, Promega). The morphological aspect of the cells was monitored all along the culture period.

\section{Differentiation of human pre-adipocytes}

Pre-adipocytes were obtained from overweight (body mass index $\left.25.4 \pm 3.1 \mathrm{~kg} / \mathrm{m}^{2}\right)$ and young $(35.5 \pm 7.3$ years old) female patients undergoing esthetic or reconstructive surgery. Pre-adipocytes were cultured for $24 \mathrm{~h}$ in $100 \mu \mathrm{l}$ of DMEM-10\% FBS in 96-well plates. They were then incubated with Caco-2 basolateral media \pm tested plant extracts diluted at $1 / 8$ (dilution defined in preliminary study described in Supplemental results) in a pro-adipogenic cocktail containing insulin, glucocorticoid, 3-isobutyl1-methylxanthine (IBMX), and thiazolinedione [29, 30]. Pre-adipocytes treated with the basal DMEM/F12 medium (undifferentiated) or treated with a PPAR $\gamma$ antagonist
(GW9662, $0.1 \mu \mathrm{m}$, M6191, Sigma) were used as negative controls of adipocyte differentiation. All conditions were performed in triplicate. The medium was changed every 2 days for up to 10 to 12 days.

\section{Quantification of lipid accumulation and of UCP1 protein expression}

After 10-12 days of culture, pre-adipocytes were fixed with $4 \%$ paraformaldehyde then washed with PBS containing $0.1 \mathrm{M}$ glycine. Following permeabilization by PBS containing 3\% BSA and $0.1 \%$ triton X100, Uncoupling Protein 1 (antibody against UCP1, U6382, Sigma) staining was performed at $4{ }^{\circ} \mathrm{C}$, overnight. Bodipy (D3922, Molecular Probes), and DAPI (4',6-Diamidino-2-Phenylindole, Dihydrochloride) (D1306, Molecular Probes) staining were performed at room temperature to stain for lipid droplets and nuclei, respectively.

Quantifications of lipid accumulation and UCP1 protein expression were collected from image acquisition and processing was performed according to the procedure specifically developed as described in the supplemental materials and methods.

\section{ATP production assay}

ATP was measured in pre-adipocytes cultured for 10-12 days in adipogenic or non-adipogenic differentiation medium, using a luminescent ATP Detection Reagent (Mitochondrial ToxGloAssay, G8000, Promega). The mitochondrial toxin Rotenone (400 nM, R8875, Sigma) was used as a negative control. DAPI fluorescent staining was performed to evaluate cell number and to normalize the luminescence signal.

\section{Adipocyte culture and measurement of lipolytic activity}

Adipocytes were incubated in Krebs Ringer Bicarbonate (KRB) buffer supplemented or not with basolateral medium from Caco- 2 cells treated with either predetermined concentrations of the extracts, at a dilution of $1 / 8$, or the prolipolytic reference products (Forskolin and Isoproterenol), at $37{ }^{\circ} \mathrm{C}$ for $2 \mathrm{~h}$. Forskolin ( $1 \mu \mathrm{m}, \mathrm{F} 6886-$ Sigma $)$ and isoproterenol $(0.1 \mu \mathrm{m}$, I6504-Sigma) were used as activators of lipolysis. Cell culture media were then collected and frozen at $-20^{\circ} \mathrm{C}$. The lipolytic activity of human adipocytes was assessed by the measurement of glycerol (Glycerol assay, GY105, Randox), and non-esterified fatty acid release (NEFA-HR2 R1 Set, 434-91795 et NEFA-HR2 R2 Set, 436-91995, Wako) in the adipocyte culture medium. 
Adipocytes were collected for DNA quantification (QuantiT $^{\text {TM PicoGreen }}{ }^{\text {TM }}$ dsDNA Assay Kit, P7589, Invitrogen) to normalize glycerol and NEFA concentrations.

\section{Statistical analysis}

Results are expressed as percentages of respective controls. Statistical analyses were performed using the Prism software (GraphPad Software). We used triplicate assays for each experiment per donor, resulting in a total of nine values for the three donors. Comparisons between the treatment and control conditions (no extract) were analyzed by

A

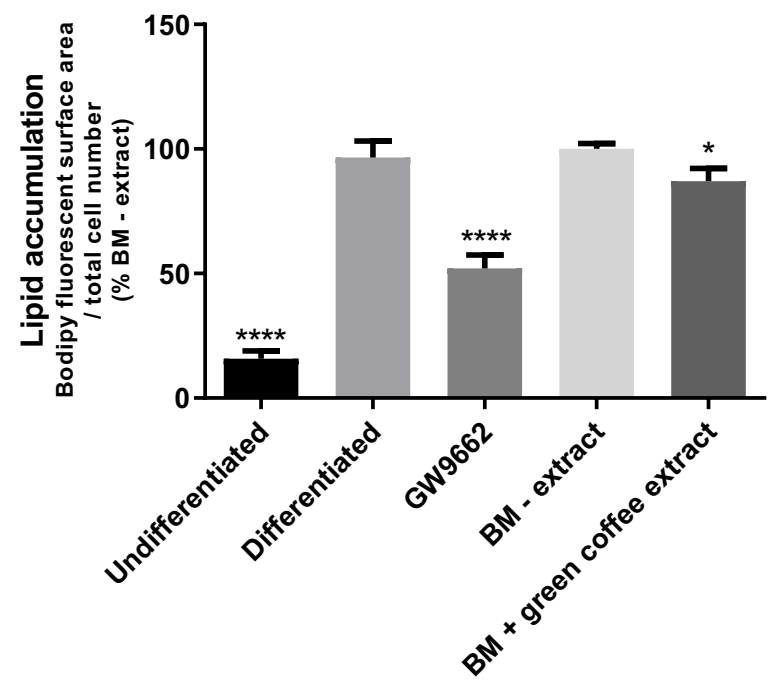

C
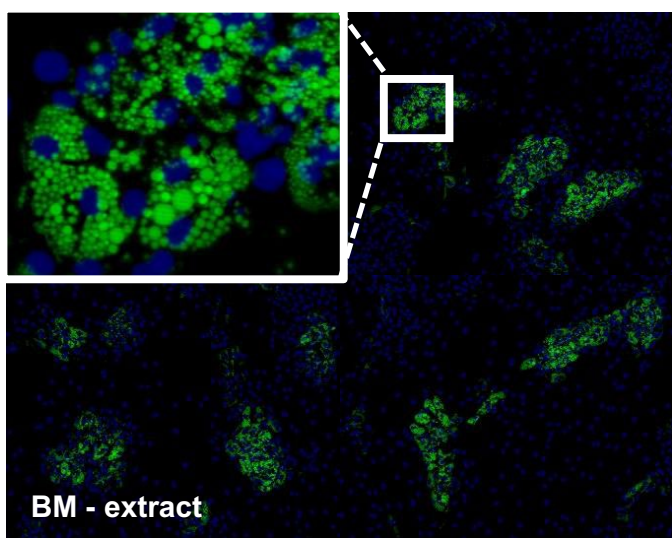

Fig. 2 Lipid accumulation in human pre-adipocytes is decreased with Caco-2 basolateral medium + green coffee extract $(\mathrm{BM}+$ green coffee extract) compared to control Caco-2 basolateral medium (BM - extract). A Quantification of lipid accumulation after BODIPY staining (fluorescent surface area relative to total cell number), $n=9$. B Percentage of differentiated cells relative to total cell number, $n=3 . * p<0.05 ; * * p<0.01 ; * * * * p<0.0001$. C Representative immunofluorescent microphotographs of lipid droplets (BODIPY in green) and nuclei (DAPI in blue) staining. Undifferentiated: pre- the Friedman test, to compare repeated data for dependent samples, followed by the Wilcoxon test, to compare paired samples two by two. Differences were considered as statistically significant when $p \leq 0.05(* p \leq 0.05 ; * * p \leq 0.01$; $* * * p \leq 0.001 ; * * * * \leq 0.0001)$.

\section{B}
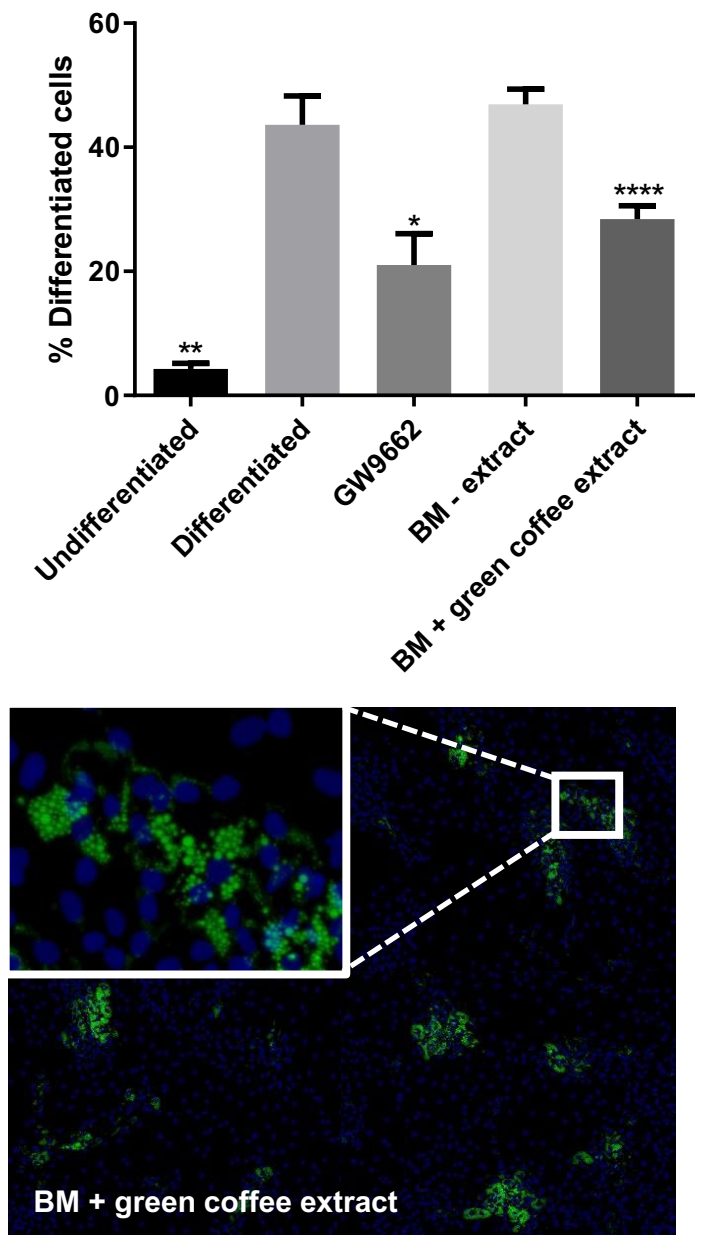

adipocytes in basal culture medium; Differentiated: pre-adipocytes in pro-adipogenic culture medium; GW9662: pre-adipocytes in proadipogenic culture medium with PPAR $\gamma$ antagonist, GW9662 $(1 \mu \mathrm{m})$; $\mathrm{BM}$ - extract: pre-adipocytes in pro-adipogenic culture medium with basolateral media of caco-2 cells not exposed to botanical extracts; $\mathrm{BM}+$ green coffee extract: pre-adipocytes in pro-adipogenic culture medium with basolateral media of caco-2 cells exposed to green coffee extract 


\section{Results}

\section{Verification of the culture system combining human Caco- 2 cells and adipose cells using green coffee extract}

\section{The effect of green coffee extract on pre-adipocyte differentiation}

After verifying the absence of cytotoxic effects (Suppl. Fig.S1), the impact of this extract on pre-adipocyte differentiation was analyzed by assessing lipid accumulation in human pre-adipocytes. GW9662, an antagonist of $\operatorname{PPAR} \gamma$, diminished lipid accumulation by about $50 \%$ compared to the BM-extract (Fig. 2A). Green coffee extract $(\mathrm{BM}+$ green coffee extract) decreased lipid accumulation by about $13 \%$ (Fig. 2A, C) compared to the BM-extract. The percentage of differentiated cells was also reduced by about $40 \%$ by green coffee extract (Fig. 2B, C).

\section{The effect of green coffee extract on the lipolytic activity of adipocytes}

Forskolin and isoproterenol increased glycerol release by about $100 \%$ and $220 \%$, respectively, and increased NEFA release by about $200 \%$. Green coffee extract $(\mathrm{BM}+$ green coffee extract) significantly increased the glycerol

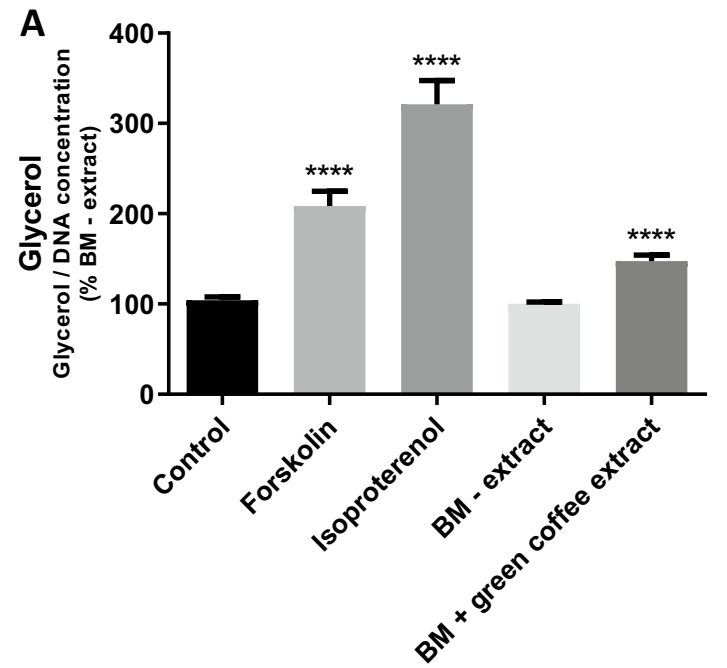

Fig. 3 Lipolytic activity of human adipocytes is increased with Caco-2 basolateral medium + green coffee extract (BM+green coffee extract) compared to control Caco-2 basolateral medium (BM - extract). A Quantification of glycerol release (concentration relative to DNA quantification), $n=9$. B Quantification of NEFA release (concentration relative to DNA quantification), $n=9$. $* * * p<0.001$; $* * * * p<0.0001$. Control: mature adipocytes in basal culture medium; Forskolin: mature adipocytes in specific adipocyte culture medium
(Fig. 3A) and NEFA (Fig. 3B) release by $50 \%$ and $120 \%$, respectively, compared to the $\mathrm{BM}-$ extract.

\section{The effect of green coffee extract on mitochondrial activity of pre-adipocytes}

Mitochondrial ATP synthase activity was analyzed by quantifying the production of ATP. As shown in Fig. 4A, treatment with the negative control rotenone decreased ATP production by $55 \%$ in differentiated pre-adipocytes. Green coffee extract (BM + green coffee extract) increased the ATP production significantly $(+20 \%)$ in differentiated pre-adipocytes when compared to BM - extract (Fig. 4A). In addition, when normalized to the total cell number, the adipogenesis inhibitor GW9662 [31], significantly inhibited UCP1 protein (-60\%) expression when compared to the BM-extract (Fig. 4B), but the green coffee extract $(B M+$ green coffee extract) did not have any effect on UCP1 levels when compared to BM-extract. However, when normalized only to the number of differentiated cells, UCP1 protein expression was significantly increased by $55 \%$ in cells differentiated in the presence of green coffee extract $(\mathrm{BM}+$ green coffee extract) compared to BM - extract (Fig. 4C, D).

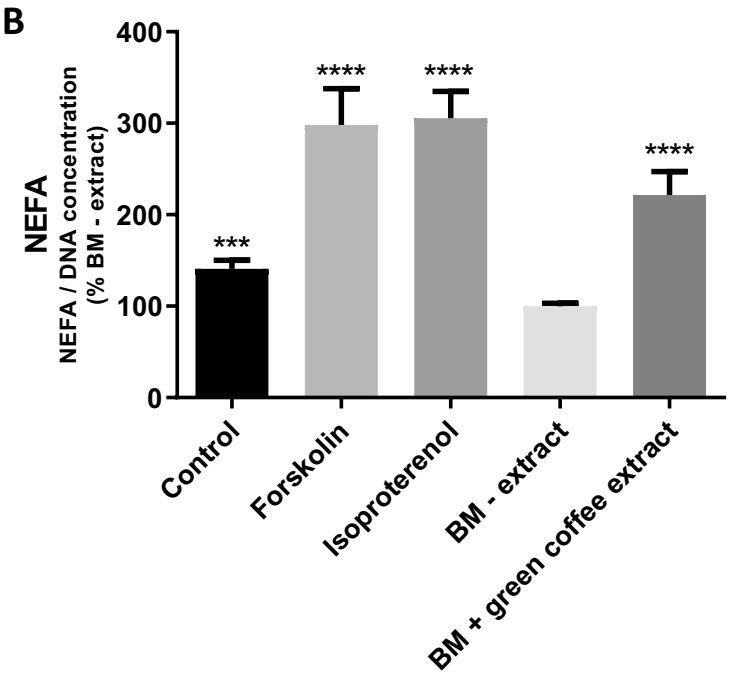

with Forskolin $(1 \mu \mathrm{m})$; Isoproterenol: mature adipocytes in specific adipocyte culture medium with Isoproterenol $(0.1 \mu \mathrm{m})$; BM extract: mature adipocytes in specific adipocyte culture medium with basolateral media of caco-2 cells not exposed to botanical extracts; $\mathrm{BM}+$ green coffee extract: mature adipocytes in specific adipocyte culture medium with basolateral media of caco- 2 cells exposed to green coffee extract 
A

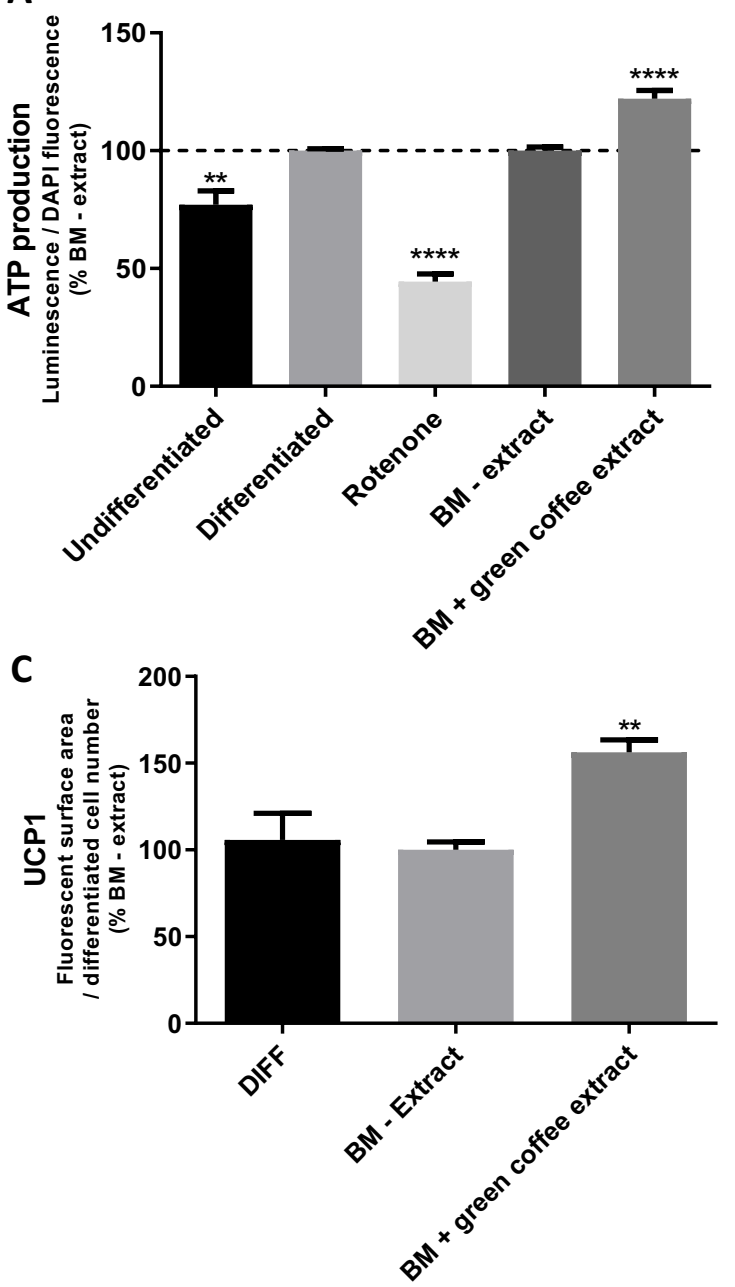

B

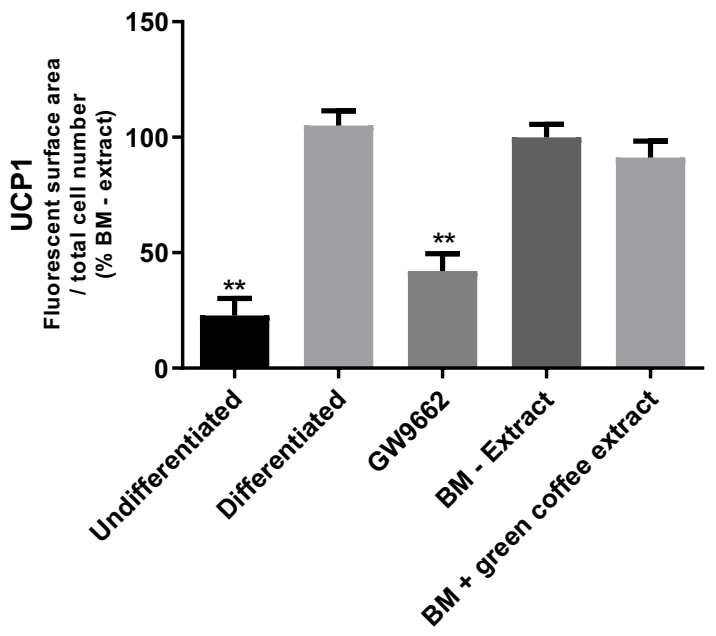

D
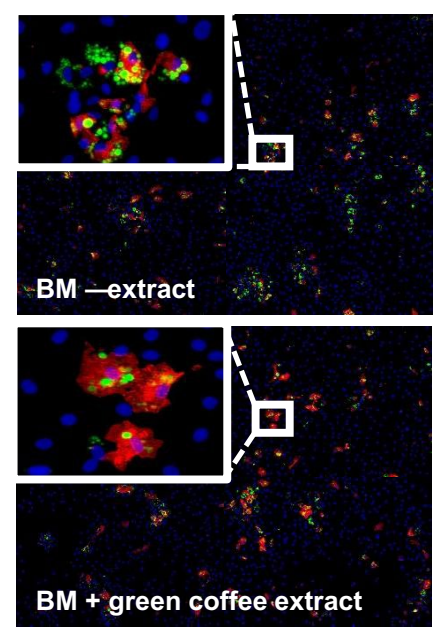

Fig. 4 Energetic metabolism of human pre-adipocytes is increased with Caco-2 basolateral medium + green coffee extract $(B M+$ green coffee extract) compared to control Caco-2 basolateral medium (BM - extract). A Quantification of ATP production (luminescence relative to DAPI fluorescence), $n=4$. B Quantification of UCP1 protein expression after immunostaining in total cells (fluorescent surface area relative to total cell number), $n=3$. C Quantification of UCP1 protein expression after immunostaining in differentiated pre-adipocytes (fluorescent surface area relative to differentiated cell number), $n=3$. $* * p<0.01 ; * * * * p<0.0001$. D Representative microphotographs of UCP1 (red), lipid accumulation (BODIPY in green)

\section{The adipocyte/Caco-2 culture system is suitable for the evaluation of the effects of 25 plant extracts on adipose cell biology}

\section{Cytotoxicity of plant extracts}

Three dilutions, $1 / 4,1 / 8$ and 1/10, of Caco-2 basolateral media were tested for their toxicity on pre-adipocytes by the eventual release of LDH and formazan production. Dilutions of $1 / 8$ and $1 / 10$ were considered not to be cytotoxic and nuclei (DAPI in blue) staining. Undifferentiated: pre-adipocytes in basal culture medium; Differentiated or DIFF: pre-adipocytes in pro-adipogenic culture medium; GW9662: pre-adipocytes in pro-adipogenic culture medium with PPAR $\gamma$ antagonist, GW9662 $(1 \mu \mathrm{m})$; Rotenone: pre-adipocytes in pro-adipogenic culture medium with mitochondrial toxin, Rotenone $(400 \mathrm{nM})$; BM - extract: preadipocytes in pro-adipogenic culture medium with basolateral media of caco-2 cells not exposed to botanical extracts; $\mathrm{BM}+$ green coffee extract: pre-adipocytes in pro-adipogenic culture medium with basolateral media of caco- 2 cells exposed to green coffee extract

for pre-adipocytes and hence the lowest dilution of $1 / 8$, was used in the subsequent analyses, so as not to dilute the extracts too much (Suppl. Fig.S3).

\section{Effects of the 25 plant extracts on pre-adipocyte differentiation and adipocyte lipolysis [32]}

The cytotoxicity of the BM from Caco-2 cells incubated with the 25 extracts $(\mathrm{BM}+$ extract latter) on pre-adipocytes was tested using the $\mathrm{LDH}$ assay. $\mathrm{BM} \pm$ products were 
A
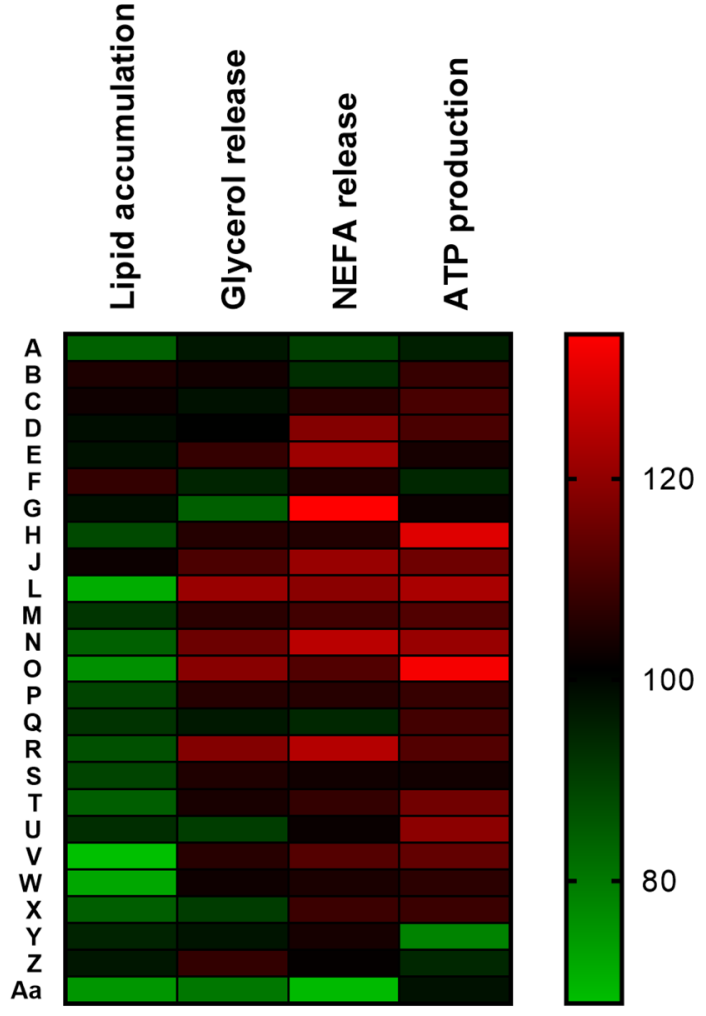

B

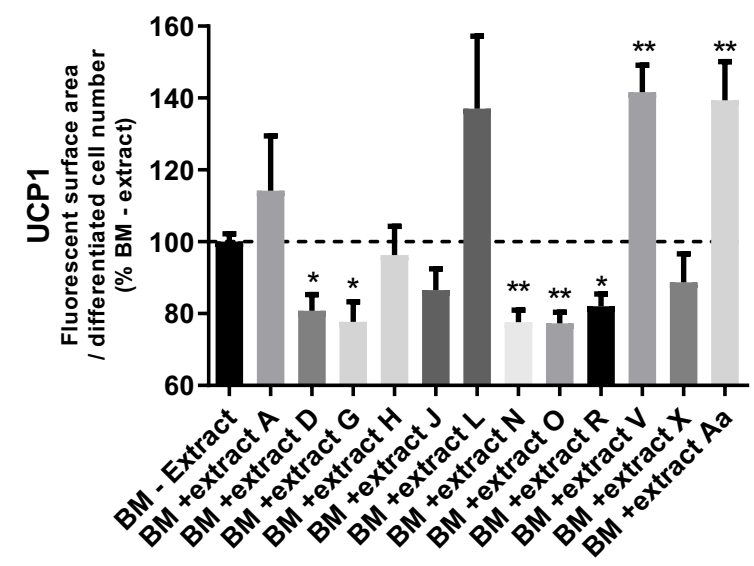

Fig. 5 Biological effects of plant extracts on human pre-adipocytes and mature adipocytes. A Heat-map illustration displaying the effects of plant extracts on lipid accumulation and ATP production in human pre-adipocytes and on glycerol and NEFA release in human mature adipocytes, $n=3$ to 6 . Each row represents a plant extract and columns represent biological parameters. The red region corresponds to stimulatory effects and green region corresponds to inhibitory effects. B Quantification of UCP1 protein expression after immunostaining in differentiated pre-adipocytes (fluorescent surface area relative to differentiated cell number), $n=3$. BM - extract: pre-adipocytes in proadipogenic culture medium with basolateral media of caco- 2 cells not exposed to botanical extracts; BM + extract LETTER (A to Aa): preadipocytes in pro-adipogenic culture medium with basolateral media of caco- 2 cells exposed to plant extracts described in Table 1
Table 2 Botanical source of seven extracts used for combination tests

\begin{tabular}{lll}
\hline Combination & Code & Vernacular name \\
\hline 1 & $\mathrm{~L}$ & Catechu \\
& $\mathrm{N}$ & Guggul \\
2 & $\mathrm{~L}$ & Catechu \\
& $\mathrm{Aa}$ & Immortelle \\
3 & $\mathrm{H}$ & Lotus \\
& $\mathrm{Aa}$ & Immortelle \\
4 & $\mathrm{O}$ & Carrot \\
& $\mathrm{V}$ & Rose Hip \\
5 & $\mathrm{~L}$ & Catechu \\
& $\mathrm{V}$ & Rose Hip \\
6 & $\mathrm{O}$ & Carrot \\
& $\mathrm{R}$ & Ceylon cinnamon \\
\hline
\end{tabular}

not cytotoxic for pre-adipocytes and did not affect their viability (Suppl. Fig.S4). Upon evaluating the effects of the extracts on pre-adipocyte differentiation, in comparison with BM-extract, two extracts, A and J, significantly increased lipid accumulation by about $15 \%$, while six extracts, L, O, P, S, T and W, significantly decreased it by $15 \%, 20 \%, 10 \%, 10 \%, 15 \%$ and $28 \%$ respectively (Fig. 5A and Suppl. Fig.S5). The others had no significant effect on lipid accumulation. Finally, the two markers of lipolysis, glycerol and NEFA release, were analyzed. Extracts J, L, $\mathrm{O}$ and $\mathrm{R}$, increased glycerol release by mature adipocytes significantly, by about $10 \%, 20 \%, 18 \%$ and $18 \%$, respectively, while two extracts, $\mathrm{G}$ and Aa decreased it by $15 \%$ and 20\%, respectively (Fig. 5A and Suppl. Fig.S5). The release of NEFA was increased by $\mathrm{L}$ and $\mathrm{N}$ extracts by about $20 \%$ and $25 \%$ and a similar trend was observed with extract R, while extract Aa decreased it by $30 \%$ (Fig. 5A and Suppl. Fig.S5).

\section{Effects of the 25 plant extracts on mitochondrial activity of differentiated pre-adipocytes}

The production of ATP by differentiated pre-adipocytes after 10-12 days of culture in pro-adipogenic medium, increased with two extracts, $\mathrm{H}$ and $\mathrm{X}$, by $+30 \%$ and $+10 \%$ respectively when compared to BM-extract. Three additional extracts $\mathrm{J}, \mathrm{L}$ and $\mathrm{O}$, showed a similar tendency to increase in this parameter. Only one extract, Y, decreased it significantly by $20 \%$, while the other extracts did not have any significant effect (Fig. 5A and Suppl. Fig.S5). 
A

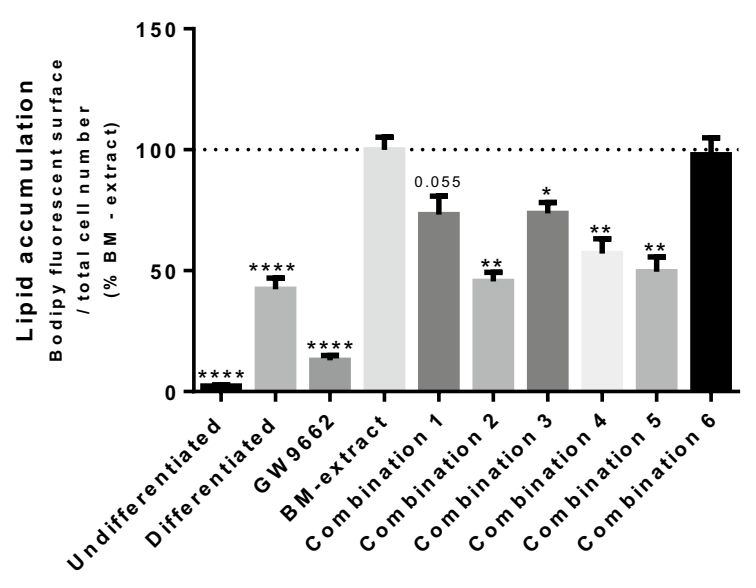

C

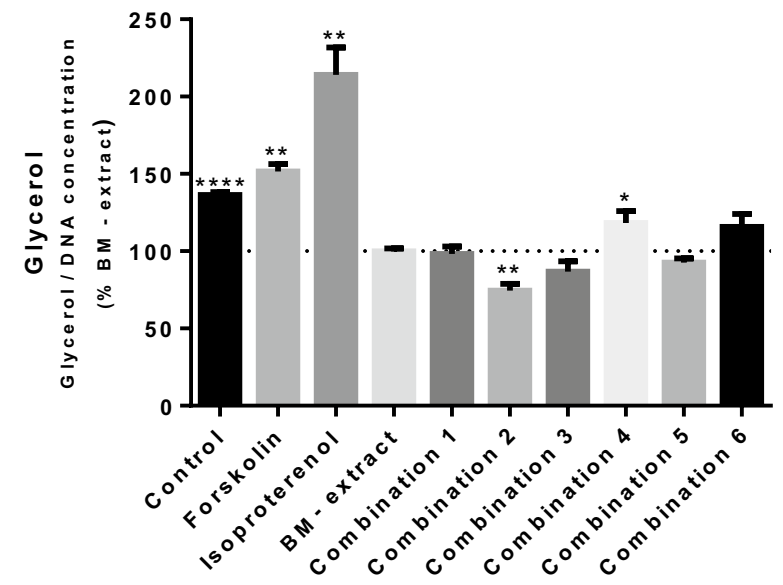

E

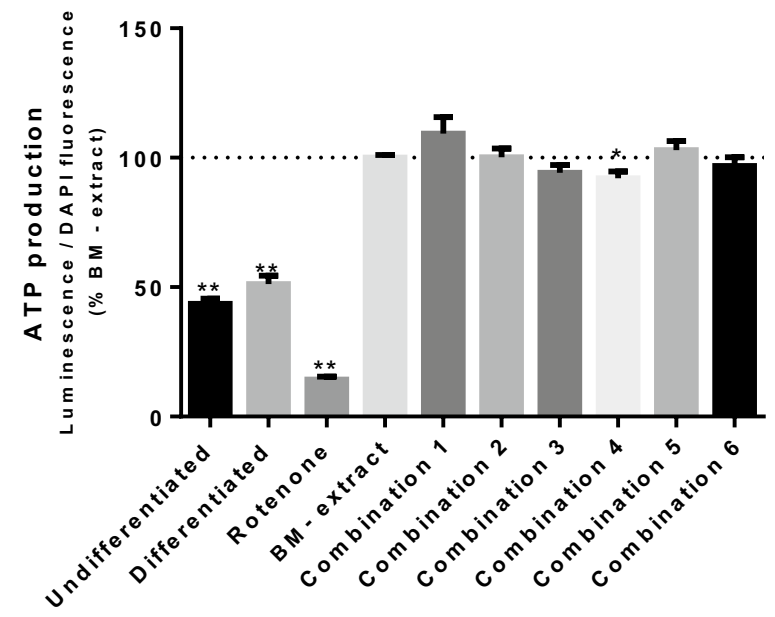

\section{UCP1 protein expression in differentiated pre-adipocytes after plant extract treatment}

Following the previous results of lipid accumulation, ATP production and lipolysis, twelve extracts (A, D, G, H, J, L, $\mathrm{N}, \mathrm{O}, \mathrm{R}, \mathrm{V}, \mathrm{X}$ and Aa) were assessed for their effects on the protein expression of UCP1 in differentiated pre-adipocytes
B

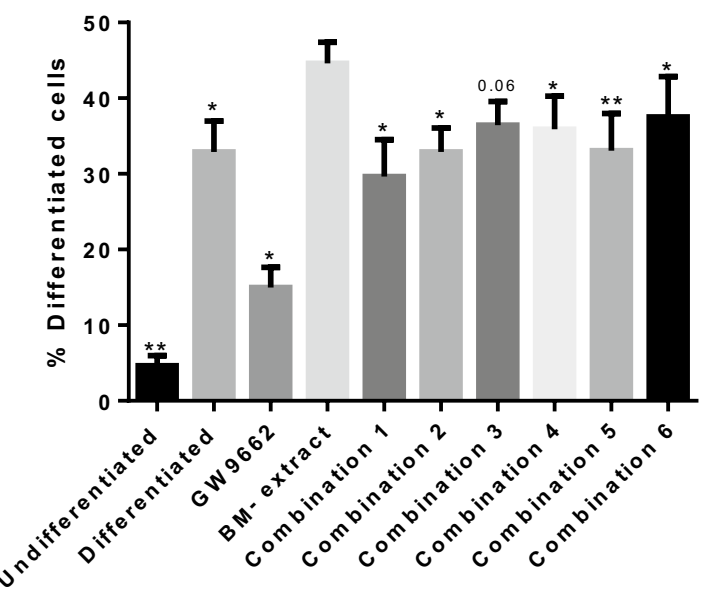

D
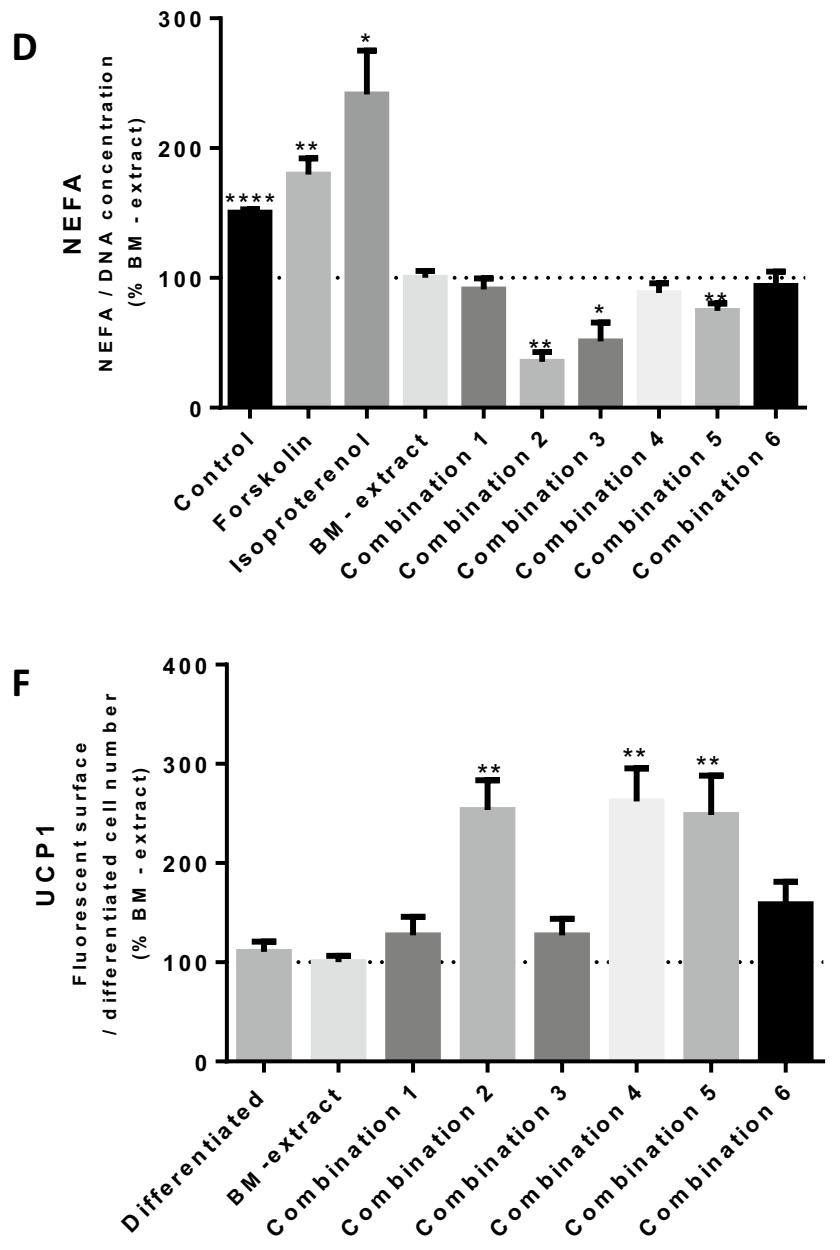

in comparison with the condition BM-extract. The expression of this protein relative to the number of differentiated cells increased significantly after treatment with $\mathrm{V}$ and $\mathrm{Aa}$ extracts by about $40 \%$ and tended to increase with extract L (Fig. 5B and Suppl. Fig.S5). The extracts D, G, N, O and R significantly decreased UCP1 expression by about $20 \%$. 
४Fig. 6 Effects of combinations of plant extracts on adipose cells. A Quantification of lipid accumulation in pre-adipocytes (fluorescent surface area relative to total cell number), $n=3$. B Percentage of differentiated cells relative to total cell number, $n=3$. ${ }^{*} p \leq 0.05$; $* * p \leq 0.01 ; * * * p \leq 0.001 ; * * * * p \leq 0.0001$. Undifferentiated: preadipocytes in basal culture medium; Differentiated: pre-adipocytes in pro-adipogenic culture medium; GW9662: pre-adipocytes in proadipogenic culture medium with PPAR $\gamma$ antagonist, GW9662 $(1 \mu \mathrm{m})$; $\mathrm{BM}$ - extract: pre-adipocytes in pro-adipogenic culture medium with basolateral media of caco-2 cells not exposed to botanical extracts; $\mathrm{BM}+$ Combination 1 to 6 : pre-adipocytes in pro-adipogenic culture medium with combination of basolateral media of caco- 2 cells exposed to plant extracts described in Table 3. C Quantification of Glycerol release in mature adipocytes (concentration relative to DNA quantification), $n=3$. D Quantification of NEFA release in mature adipocytes (concentration relative to DNA quantification), $n=3$. ${ }^{*} p \leq 0.05 ; * * p \leq 0.01 ; * * * p \leq 0.001 ; * * * * p \leq 0.0001$. Control: mature adipocytes in basal culture medium; Forskolin: mature adipocytes in specific adipocyte culture medium with Forskolin $(1 \mu \mathrm{m})$; Isoproterenol: mature adipocytes in specific adipocyte culture medium with Isoproterenol $(0.1 \mu \mathrm{m}) ; \mathrm{BM}$ - extract: mature adipocytes in specific adipocyte culture medium with basolateral media of caco- 2 cells not exposed to botanical extracts. BM+Combination 1 to 6 : mature adipocytes in specific adipocyte culture medium with combination of basolateral media of caco- 2 cells exposed plant extracts described in Table 3. E Quantification of ATP production in pre-adipocytes (luminescence relative to DAPI fluorescence), $n=3$. ${ }^{*} p \leq 0.05 ; * * p \leq 0.01$; $* * * p \leq 0.001$; **** $p \leq 0.0001$. Undifferentiated: pre-adipocytes in basal culture medium; Differentiated or DIFF: pre-adipocytes in proadipogenic culture medium; Rotenone: pre-adipocytes in pro-adipogenic culture medium with mitochondrial toxin, Rotenone (400 nM); $\mathrm{BM}$ - extract: pre-adipocytes in pro-adipogenic culture medium with basolateral media of caco-2 cells not exposed to botanical extracts; $\mathrm{BM}+$ Combination 1 to 6 : pre-adipocytes in pro-adipogenic culture medium with combination of basolateral media of caco-2 cells exposed to plant extracts described in Table 3. F Quantification of UCP1 protein expression after immunostaining in differentiated preadipocytes (fluorescent surface area relative to differentiated cell number), $n=3$. $* p \leq 0.05 ; * * p \leq 0.01 ; * * * p \leq 0.001 ; * * * * p \leq 0.0001$. Differentiated: preadipocytes in proadipogenic culture medium; $\mathrm{BM}$ - extract: preadipocytes in proadipogenic culture medium with basolateral media of caco- 2 cells not exposed to botanical extracts; $\mathrm{BM}+$ Combination 1 to 6 : preadipocytes in proadipogenic culture medium with combination of basolateral media of caco-2 cells exposed to plant extracts described in Table 3

To sum up (Suppl. Fig.S5), only a few of the extracts exhibited an overall adipocyte modulation similar to green coffee extract (H, L, N, O, R, V and Aa), even though they were tested at a much lower concentration (especially $\mathrm{N}, \mathrm{O}$ and R). Only V and Aa increased the expression of the UCP1 protein in differentiated pre-adipocytes, and in a comparable manner to green coffee. As these extracts could have different specific modulation of adipocyte activities, a combination of them was tested to assess if a synergistic activity could be achieved.

\section{Effects of 6 combinations of plant extracts on pre-adipocytes after $24 \mathrm{~h}$ of treatment on Caco-2 cells}

In this part of the study, we aimed to evaluate the effects of plant extract combinations (Table 2). In total, six combinations were tested. These extracts were selected according to their potential properties as "fat mobilizers" (increasing lipolysis), "fat burners" (increasing energetic metabolism) or "fat inhibitors" (decreasing lipid accumulation).

\section{Effects of plant extracts combinations on lipid accumulation in pre-adipocytes and on adipocyte lipolysis}

After assessing the absence of cytotoxicity of the extract combinations (Suppl. Fig.S6), pre-adipocyte differentiation was evaluated by quantifying their lipid accumulation. As expected, the PPAR $\gamma$ antagonist GW9662 diminished lipid accumulation significantly by $90 \%$ when compared to BM - extract. Interestingly, four combinations, 2, 3, 4 and 5 significantly decreased lipid accumulation in pre-adipocytes by $55 \%, 25 \%, 40 \%$ and $50 \%$, respectively, while combination 1 tended to decrease it, and combination 6 did not present any effects (Fig. 6A). The percentage of differentiated cells was also reduced by all the combinations (Fig. 6B). As for forskolin or isoproterenol treatment, only combination 4 showed potent lipolytic properties as demonstrated by the significant increase in glycerol release $(+20 \%)$, whereas no increase of NEFA was measured (Fig. 6C, D). Combination 2 significantly reduced both the glycerol and NEFA release and to a lower extent combination 3 , which showed only a minor lipolytic effect (Fig. 6C, D).

\section{Mitochondrial activity and UCP1 expression after treatment of pre-adipocytes with combinations of plant extracts}

Evaluation of ATP production showed that combination 4 exhibited a significant inhibitory effect $(-10 \%)$, while the other combinations did not have any effect (Fig. 6E). This observation correlated with the significant increase of UCP1 expression $(+150 \%)$ with combination 4 (Fig. 6F). Similar increase in UCP1 expression was observed with combinations 2 and 5 without affecting ATP production (Fig. 6E, F).

Taken together (Table 3), these data indicate that combinations 2, 3, 4 and 5 significantly inhibited lipid accumulation in differentiated pre-adipocytes, with the highest efficacy achieved with combinations 2 (Acacia catechu and Immortelle-45.5\%) and 5 (Acacia catechu and Rose hip$49.6 \%$ ). A moderate effect on lipolysis was observed with combination 4 (and contrary to combinations 2 and 5) only, while for all combinations, modulations of ATP were not significant or were very weak. Finally, combinations 2, 4 
Table 3 Summary table of biological effects of plant extract combinations on adipose cells

\begin{tabular}{|c|c|c|c|c|c|c|c|c|}
\hline Combination & $\begin{array}{l}\text { Vernacular } \\
\text { name }\end{array}$ & Code & $\begin{array}{l}\text { Lipid accumu- } \\
\text { lation }\end{array}$ & $\begin{array}{l}\text { Glycerol } \\
\text { release }\end{array}$ & NEFA release & $\begin{array}{l}\text { ATP Produc- } \\
\text { tion }\end{array}$ & $\begin{array}{l}\text { UCP1 expres- } \\
\text { sion/Total cell } \\
\text { number }\end{array}$ & $\begin{array}{l}\text { UCP1 expres- } \\
\text { sion/Differenti- } \\
\text { ated cells }\end{array}$ \\
\hline 1 & $\begin{array}{l}\text { Catechu } \\
\text { Guggul }\end{array}$ & $\begin{array}{l}\mathrm{L} \\
\mathrm{N}\end{array}$ & $73.21(7.64)$ & $98.26(4.79)$ & $91.20(8.40)$ & $109.29(6.40)$ & $100.50(10.27)$ & $127.22(18.64)$ \\
\hline 2 & $\begin{array}{l}\text { Catechu } \\
\text { Immortelle }\end{array}$ & $\begin{array}{l}\mathrm{L} \\
\mathrm{Aa}\end{array}$ & $45.52 * *(3.82)$ & $74.38 * *(4.45)$ & $35.38 * *(7.51)$ & $100.20(3.35)$ & $\begin{array}{c}146.69^{*} \\
(13.67)\end{array}$ & $253.42 * *(30.17)$ \\
\hline 3 & $\begin{array}{l}\text { Lotus } \\
\text { Immortelle }\end{array}$ & $\begin{array}{l}\mathrm{H} \\
\mathrm{Aa}\end{array}$ & $73.65^{*}(4.57)$ & 86.87 (6.64) & $51.13 *(14.53)$ & $94.20(3.04)$ & $110.38(7.76)$ & $127.12(16.87)$ \\
\hline 4 & $\begin{array}{l}\text { Carrot } \\
\text { Rose Hip }\end{array}$ & $\begin{array}{l}\mathrm{O} \\
\mathrm{V}\end{array}$ & $57.05 * *(6.17)$ & $118.24 *(7.71)$ & $88.38(7.49)$ & $92.11 *(2.60)$ & $\begin{array}{r}168.81 * \\
(14.52)\end{array}$ & $262.13 * *(33.54)$ \\
\hline 5 & $\begin{array}{l}\text { Catechu } \\
\text { Rose Hip }\end{array}$ & $\begin{array}{l}\mathrm{L} \\
\mathrm{V}\end{array}$ & $49.57 * *(6.11)$ & $92.66(2.75)$ & $74.74 * *(5.56)$ & $102.96(3.51)$ & $\begin{array}{r}135.54 * \\
(12.72)\end{array}$ & $248.51 * *(39.69)$ \\
\hline 6 & $\begin{array}{l}\text { Carrot } \\
\text { Ceylon cin- } \\
\text { namon }\end{array}$ & $\begin{array}{l}\mathrm{O} \\
\mathrm{R}\end{array}$ & $97.90(7.06)$ & $115.72(8.29)$ & 93.89 (11.07) & $96.83(3.42)$ & $\begin{array}{r}157.76^{*} \\
(19.51)\end{array}$ & 158.55 (22.67) \\
\hline
\end{tabular}

Results were expressed in percentage relative to the control

Mean \pm SEM (standard error of the mean) of $n=3$

${ }^{*} p<0.05$

${ }^{* *} p<0.01$

(Daucus carota and Rose hip) and 5 exhibited the highest significant effects seen in the increase of UCP1 protein expression in differentiated pre-adipocytes $(253.4 \%, 262.1 \%$ and $248.5 \%$ respectively).

\section{Discussion}

The accumulation of fat leads to obesity and hence to potentially serious health problems, such as cardiovascular disease or diabetes. Much time and effort have been put in finding solutions to either minimize fat accumulation in the first place, or to reduce stored fat through increased metabolism or changing adipose composition. In recent years, many patients and even the general population resort to plant derived products to control or reduce their fat buildup. However, the effectiveness of these substances on the adipose tissue has not always been looked at or confirmed. In this study, we aimed to bring together an in vitro model of the absorption of plant extracts by the intestinal barrier with their eventual effect on human adipose tissue and hence to find the most active extracts to this effect.

Hence, this bi-phasic in vitro trial compared botanical extract potencies intended for oral use for their biological activities on lipid accumulation, adipocyte lipolysis or energy metabolism using an in vitro model combining intestinal Caco- 2 cells and human adipose cells. First, this culture system was verified by establishing its dose-dependent response using a standardized well-known botanical ingredient, green coffee. Second, a variety of botanical extracts were differentiated from each other by determining the differences in the way they regulate adipocyte physiology. Finally, the most effective extracts, and their combinations, were used to characterize and to further investigate their actions on adipose cells.

The first part of the model was represented by a monolayer of Caco- 2 cells to mimic intestinal passage, as in, the absorption of substances from the internal-side of the epithelial membrane, partial metabolization of the substances by the epithelial cells, and the secretion of the metabolites as well as digestive enzymes into the external-milieu of the epithelial cell. Consequently, in this way, the digestion and release of plant extracts were at least partially considered in this model prior to further in vitro investigation on adipose cells.

To start with, all plant products were extracted with a standard aqueous recipe to recover soluble compounds which would then be released into the GI tract in accordance with dietary botanicals intended for oral use (pills or capsules). Previous caco-2 trials have successfully shown that Caco-2 cells absorb hydrophilic compounds, in much the same way as in vivo intestinal absorption [19, 20, 40], despite some limitations in the mechanisms of bioavailability, such as tissue distribution specificity and interaction with other active compounds.

The second part of the model consisted of the quantification of the biological effects on human adipose cells of plants extract after Caco-2 barrier passage. 
To verify the functionality and the biological relevance of this bi-phasic system for our purposes, different doses of a green coffee extract with standardized caffeine and chlorogenic acid concentrations, which are known for their in vivo lipolytic actions in adipose tissue [33-36], were applied to Caco-2 cells. Each of the twenty-five plant extracts was then screened on the same biological parameters and compared with the green coffee extract. Out of these, only seven plant extracts were retained due to their inhibitory effects on lipid accumulation or thermogenic effects through stimulated UCP1 expression or pro-lipolytic activities or which presented two or three of these effects simultaneously: Acacia catechu (bark), Immortelle, Rose hip (fruit), Daucus carota (seeds), Ceylon Cinnamon, Lotus (flower) and Guggul (exudate).

Acacia catechu has previously been described as having anti-oxidant, anti-inflammatory and chemoprotective properties [37, 38] whereas Immortelle is known as an antimicrobial and anti-inflammatory agent [39]. For the first time, our study demonstrates that Acacia catechu and Immortelle can modulate adipose cell biology in stimulating lipolysis and mitochondrial activity, respectively. Moreover, they both similarly reduced lipid accumulation in human preadipocytes. Interestingly, together, they presented better bio-effects than when tested separately, particularly related to UCP1 expression (+153.4\% compared to the control condition).

Rose Hip is commonly used as a vitamin C supplement and is known for its antioxidant and anti-inflammatory properties. Preclinical studies have shown that Rose hip prevents body weight gain and visceral fat mass accumulation in non-obese mice [40] and inhibits lipid accumulation in a transformed cell line derived from mouse 3T3-L1 fibroblasts [41]. Furthermore, a clinical study performed on 32 overweight subjects showed that Rose Hip supplements reduced abdominal total fat, visceral fat and body weight [42]. When tested individually, our study revealed that Rose Hip had the best effect in reducing lipid accumulation (-33\% compared to the control condition) and UCP-1 expression in human pre-adipocytes ( $+40 \%$ compared to the control condition), which could explain the clinical data described above. When associated with Acacia catechu, a significant decrease in lipid accumulation and a stronger induction of UCP1 protein expression were observed suggesting synergistic effects of these two extracts, $(+148.5 \%$ compared to the control condition).

Furthermore, several studies, mainly one in vivo study performed in rats fed a high-fat diet reported that supplementation with carrots led to a decrease in fat mass and weight gain [43-45]. However, the present study showed that although Daucus carota seeds activated adipocyte lipolysis and inhibited lipid accumulation in pre-adipocytes, they failed to induce energy metabolism and thermogenesis.
Nevertheless, its association with Rose Hip produced the best bio-effect, including stimulated lipolysis, reduced lipid accumulation, and synergistic thermogenic activity $(+162.1 \%$ UCP1 expression compared to the control condition).

Ceylon Cinnamon is considered able to mimic the effects of insulin while promoting 3T3-L1 pre-adipocyte differentiation [46] and upregulating the expression of UCP-1 [47]. However, our study shows that Ceylon Cinnamon alone, induced lipolysis in mature adipocytes and diminished lipid accumulation without affecting the energy metabolism of pre-adipocytes.

Of the seven individual extracts selected, lotus was the only one that has previously been shown to exhibit inhibitory effects on lipid accumulation and on the expression of adipogenic transcription factors in human pre-adipocytes [48-51]. However, we did not find any effect on lipolytic activity, but could confirm the anti-adipogenic effect of the Lotus flower extract and its stimulatory effect on energy metabolism. Furthermore, its combination with Immortelle did not have any added biological interest on lipid accumulation in pre-adipocytes.

Finally, Guggul has already been studied for its antiadipogenic properties due to its main component, Guggulsterone, which has been shown to inhibit adipogenesis, to induce apoptosis and to stimulate lipolysis in 3T3-L1 cells $[52,53]$. In our model, its lipolytic activity in mature human adipocytes and its inhibitory effect on lipid accumulation in human pre-adipocytes, were confirmed. In addition, a novel potential adipose thermogenic activity of this extract was also identified. The combination of Guggul with Acacia catechu improved its inhibitory effect on lipid accumulation and interestingly, demonstrated its capacity of inducing mitochondrial activity. However, complementary investigations should be considered to further support the actions of these botanical extract, such as clinical studies in obese subjects. Furthermore, as hypertrophied adipocytes produce pro-inflammatory cytokines and chemokines [29,54], contributing to the chronic inflammation associated with obesity, it would also be interesting to assess the potential of these extracts in modulating chronic inflammation of adipose tissue in vivo.

In conclusion, we have tested a co-culture model, combining human intestinal and adipose cells which is also taken into account the intestinal passage of oral plant extracts. In addition, this model was primarily verified using, as a standard, green coffee extract, due to its caffeine and chlorogenic acid concentrations.

As a proof of concept, botanical extracts were categorized and the best were chosen according to their different activities in modulating human adipose tissue biology, such as lipolysis, lipid accumulation, energetic homeostasis and 
thermogenesis activation by UCP1 protein expression. In particular, certain paired combinations of Catechu, Immortelle, Carrot and Rose hip showed higher inhibition of lipid accumulation and exceptional activation of thermogenic potency when compared to each the extracts separately (including green coffee), and to other combinations tested. However, further robust in vivo trials would be necessary to validate the prospective interest of these compounds for application on humans.

Supplementary Information The online version contains supplementary material available at https://doi.org/10.1007/s00394-021-02794-8.

\section{Declarations}

Conflict of interest This study was sponsored by Nexira and D.G is a current employee of this company.

Open Access This article is licensed under a Creative Commons Attribution 4.0 International License, which permits use, sharing, adaptation, distribution and reproduction in any medium or format, as long as you give appropriate credit to the original author(s) and the source, provide a link to the Creative Commons licence, and indicate if changes were made. The images or other third party material in this article are included in the article's Creative Commons licence, unless indicated otherwise in a credit line to the material. If material is not included in the article's Creative Commons licence and your intended use is not permitted by statutory regulation or exceeds the permitted use, you will need to obtain permission directly from the copyright holder. To view a copy of this licence, visit http://creativecommons.org/licenses/by/4.0/.

\section{References}

1. Obesity and overweight. http://www.who.int/news-room/factsheets/detail/obesity-and-overweight. Accessed 4 Dec 2018

2. Jung UJ, Choi M-S (2014) Obesity and its metabolic complications: the role of adipokines and the relationship between obesity, inflammation, insulin resistance, dyslipidemia and nonalcoholic fatty liver disease. Int J Mol Sci 15:6184-6223. https://doi.org/10. 3390/ijms 15046184

3. Gutierrez DA, Puglisi MJ, Hasty AH (2009) Impact of increased adipose tissue mass on inflammation, insulin resistance, and dyslipidemia. Curr Diab Rep 9:26-32

4. Mraz M, Haluzik M (2014) The role of adipose tissue immune cells in obesity and low-grade inflammation. J Endocrinol 222:R113-127. https://doi.org/10.1530/JOE-14-0283

5. Grant RW, Dixit VD (2015) Adipose tissue as an immunological organ. Obesity (Silver Spring) 23:512-518. https://doi.org/10. 1002/oby.21003

6. Kusminski CM, Bickel PE, Scherer PE (2016) Targeting adipose tissue in the treatment of obesity-associated diabetes. Nat Rev Drug Discov 15:639-660. https://doi.org/10.1038/nrd.2016.75

7. Bastard J-P, Fève B (2013) Physiologie et physiopathologie du tissu adipeux. Springer-Verlag, Paris

8. Parlee SD, Lentz SI, Mori H, MacDougald OA (2014) Quantifying size and number of adipocytes in adipose tissue. Meth Enzymol 537:93-122. https://doi.org/10.1016/B978-0-12-411619-1. 00006-9
9. Spalding KL, Arner E, Westermark PO et al (2008) Dynamics of fat cell turnover in humans. Nature 453:783-787. https://doi. org/10.1038/nature06902

10. Fenzl A, Kiefer FW (2014) Brown adipose tissue and thermogenesis. Horm Mol Biol Clin Investig 19:25-37. https://doi.org/ 10.1515/hmbci-2014-0022

11. Tseng Y-H, Cypess AM, Kahn CR (2010) Cellular bioenergetics as a target for obesity therapy. Nat Rev Drug Discov 9:465-482. https://doi.org/10.1038/nrd3138

12. Yoneshiro T, Saito M (2015) Activation and recruitment of brown adipose tissue as anti-obesity regimens in humans. Ann Med 47:133-141. https://doi.org/10.3109/07853890.2014. 911595

13. Harms M, Seale P (2013) Brown and beige fat: development, function and therapeutic potential. Nat Med 19:1252-1263. https://doi. org/10.1038/nm.3361

14. Reboul E, Abou L, Mikail C et al (2005) Lutein transport by Caco-2 TC-7 cells occurs partly by a facilitated process involving the scavenger receptor class B type I (SR-BI). Biochem J. https:// doi.org/10.1042/BJ20040554

15. Sun H, Chow EC, Liu S et al (2008) The Caco-2 cell monolayer: usefulness and limitations. Expert Opin Drug Metab Toxicol 4:395-411. https://doi.org/10.1517/17425255.4.4.395

16. Ishihara R, Mizuno Y, Miwa A et al (2015) Intestinal epithelial cells promote secretion of leptin and adiponectin in adipocytes. Biochem Biophys Res Commun 458:362-368. https://doi.org/10. 1016/j.bbrc.2015.01.118

17. Wu Z, Tan J, Chi Y et al (2018) Mesenteric adipose tissue contributes to intestinal barrier integrity and protects against nonalcoholic fatty liver disease in mice. Am J Physiol Gastrointest Liver Physiol 315:G659-G670. https://doi.org/10.1152/ajpgi.00079. 2018

18. Berger E, Géloën A (2019) Adipocytes as lipid sensors of oleic acid transport through a functional Caco-2/HT29-MTX intestinal barrier. Adipocyte 8:83-97. https://doi.org/10.1080/21623945. 2019.1580842

19. Liu X, Cervantes C, Liu F (2017) Common and distinct regulation of human and mouse brown and beige adipose tissues: a promising therapeutic target for obesity. Protein Cell 8:446-454. https://doi. org/10.1007/s13238-017-0378-6

20. Zuriaga MA, Fuster JJ, Gokce N, Walsh K (2017) Humans and mice display opposing patterns of "Browning" gene expression in visceral and subcutaneous white adipose tissue depots. Front Cardiovasc Med 4:27. https://doi.org/10.3389/fcvm.2017.00027

21. D'Archivio M, Filesi C, Varì R et al (2010) Bioavailability of the polyphenols: status and controversies. Int J Mol Sci 11:13211342. https://doi.org/10.3390/ijms11041321

22. Yang CS et al (2019) Bioavailability issues in studying the health effects of plant polyphenolic compounds. - PubMed - NCBI. https://www.ncbi.nlm.nih.gov/pubmed/18551457. Accessed 5 Feb 2019

23. Manach C, Williamson G, Morand C et al (2005) Bioavailability and bioefficacy of polyphenols in humans. I. Review of 97 bioavailability studies. Am J Clin Nutr 81:230S-242S. https://doi.org/ 10.1093/ajen/81.1.230S

24. Marín L, Miguélez EM, Villar CJ, Lombó F (2015) Bioavailability of dietary polyphenols and gut microbiota metabolism: antimicrobial properties. Biomed Res Int 2015:905215. https://doi.org/10. $1155 / 2015 / 905215$

25. Scotini E, Carpenedo F, Fassina G (1983) New derivatives of methyl-xanthines: effect of thiocaffeine thiotheophylline and 8-phenyltheophylline on lipolysis and on phosphodiesterase activities. Pharmacol Res Commun 15:131-143. https://doi.org/ 10.1016/s0031-6989(83)80055-1

26. Mitani T, Nagano T, Harada K et al (2017) Caffeine-stimulated intestinal epithelial cells suppress lipid accumulation in 
adipocytes. J Nutr Sci Vitaminol (Tokyo) 63:331-338. https:// doi.org/10.3177/jnsv.63.331

27. Kogure A, Sakane N, Takakura Y et al (2002) Effects of caffeine on the uncoupling protein family in obese yellow KK mice. Clin Exp Pharmacol Physiol 29:391-394. https://doi.org/10.1046/j. 1440-1681.2002.03675.x

28. Gaibelet G, Allart S, Tercé F et al (2015) Specific cellular incorporation of a pyrene-labelled cholesterol: lipoprotein-mediated delivery toward ordered intracellular membranes. PLoS ONE 10:e0121563. https://doi.org/10.1371/journal.pone.0121563

29. Lacasa D, Taleb S, Keophiphath M et al (2007) Macrophagesecreted factors impair human adipogenesis: involvement of proinflammatory state in preadipocytes. Endocrinology 148:868-877. https://doi.org/10.1210/en.2006-0687

30. Keophiphath M, Priem F, Jacquemond-Collet I et al (2009) 1,2-vinyldithiin from garlic inhibits differentiation and inflammation of human preadipocytes. J Nutr 139:2055-2060. https:// doi.org/10.3945/jn.109.105452

31. Yu W-H, Li F-G, Chen X-Y et al (2012) PPAR $\gamma$ suppression inhibits adipogenesis but does not promote osteogenesis of human mesenchymal stem cells. Int J Biochem Cell Biol 44:377-384. https:// doi.org/10.1016/j.biocel.2011.11.013

32. Skolnik S, Lin X, Wang $\mathbf{J}$ et al (2010) Towards prediction of in vivo intestinal absorption using a 96-well Caco-2 assay. J Pharm Sci 99:3246-3265. https://doi.org/10.1002/jps.22080

33. Aoyagi R, Funakoshi-Tago M, Fujiwara Y, Tamura H (2014) Coffee inhibits adipocyte differentiation via inactivation of PPAR $\gamma$. Biol Pharm Bull 37:1820-1825

34. Choi B-K, Park S-B, Lee D-R et al (2016) Green coffee bean extract improves obesity by decreasing body fat in high-fat dietinduced obese mice. Asian Pac J Trop Med 9:635-643. https:// doi.org/10.1016/j.apjtm.2016.05.017

35. Stohs SJ, Badmaev V (2016) A review of natural stimulant and non-stimulant thermogenic agents. Phytother Res 30:732-740. https://doi.org/10.1002/ptr.5583

36. Su S-H, Shyu H-W, Yeh Y-T et al (2013) Caffeine inhibits adipogenic differentiation of primary adipose-derived stem cells and bone marrow stromal cells. Toxicol In Vitro 27:1830-1837. https://doi.org/10.1016/j.tiv.2013.05.011

37. Stohs SJ, Bagchi D (2015) Antioxidant, anti-inflammatory, and chemoprotective properties of Acacia catechu heartwood extracts. Phytother Res 29:818-824. https://doi.org/10.1002/ptr.5335

38. Burnett BP, Jia Q, Zhao Y, Levy RM (2007) A medicinal extract of Scutellaria baicalensis and Acacia catechu acts as a dual inhibitor of cyclooxygenase and 5-lipoxygenase to reduce inflammation. J Med Food 10:442-451. https://doi.org/10.1089/jmf.2006. 255

39. Antunes Viegas D, Palmeira-de-Oliveira A, Salgueiro L et al (2014) Helichrysum italicum: from traditional use to scientific data. J Ethnopharmacol 151:54-65. https://doi.org/10.1016/j.jep. 2013.11.005

40. Ninomiya K, Matsuda H, Kubo M et al (2007) Potent anti-obese principle from Rosa canina: structural requirements and mode of action of trans-tiliroside. Bioorg Med Chem Lett 17:3059-3064. https://doi.org/10.1016/j.bmcl.2007.03.051

41. Nagatomo A, Nishida N, Matsuura Y, Shibata N (2013) Rosehip extract inhibits lipid accumulation in white adipose tissue by suppressing the expression of peroxisome proliferator-activated receptor gamma. Prev Nutr Food Sci 18:85-91. https://doi.org/ 10.3746/pnf.2013.18.2.085

42. Nagatomo A, Nishida N, Fukuhara I et al (2015) Daily intake of rosehip extract decreases abdominal visceral fat in preobese subjects: a randomized, double-blind, placebo-controlled clinical trial. Diabetes Metab Syndr Obes 8:147-156. https://doi.org/10. 2147/DMSO.S78623

43. El-Houri RB, Kotowska D, Christensen KB et al (2015) Polyacetylenes from carrots (Daucus carota) improve glucose uptake in vitro in adipocytes and myotubes. Food Funct 6:2135-2144. https://doi.org/10.1039/c5fo00223k

44. Park S, Kang S, Jeong D-Y et al (2015) Cyanidin and malvidin in aqueous extracts of black carrots fermented with Aspergillus oryzae prevent the impairment of energy, lipid and glucose metabolism in estrogen-deficient rats by AMPK activation. Genes Nutr 10:455. https://doi.org/10.1007/s12263-015-0455-5

45. El-Houri RB, Kotowska D, Olsen LCB et al (2014) Screening for bioactive metabolites in plant extracts modulating glucose uptake and fat accumulation. Evid Based Complement Alternat Med 2014:156398. https://doi.org/10.1155/2014/156398

46. Shen Y, Honma N, Kobayashi K et al (2014) Cinnamon extract enhances glucose uptake in 3T3-L1 adipocytes and C2C12 myocytes by inducing LKB1-AMP-activated protein kinase signaling. PLoS ONE 9:e87894. https://doi.org/10.1371/journal.pone.00878 94

47. Shen Y, Fukushima M, Ito Y et al (2010) Verification of the antidiabetic effects of cinnamon (Cinnamomum zeylanicum) using insulin-uncontrolled type 1 diabetic rats and cultured adipocytes. Biosci Biotechnol Biochem 74:2418-2425. https://doi.org/10. 1271/bbb.100453

48. Wu C-H, Yang M-Y, Chan K-C et al (2010) Improvement in highfat diet-induced obesity and body fat accumulation by a Nelumbo nucifera leaf flavonoid-rich extract in mice. J Agric Food Chem 58:7075-7081. https://doi.org/10.1021/jf101415v

49. Ohkoshi E, Miyazaki H, Shindo K et al (2007) Constituents from the leaves of Nelumbo nucifera stimulate lipolysis in the white adipose tissue of mice. Planta Med 73:1255-1259. https://doi.org/ 10.1055/s-2007-990223

50. Ono Y, Hattori E, Fukaya Y et al (2006) Anti-obesity effect of Nelumbo nucifera leaves extract in mice and rats. J Ethnopharmacol 106:238-244. https://doi.org/10.1016/j.jep.2005.12.036

51. You JS, Lee YJ, Kim KS et al (2014) Ethanol extract of lotus (Nelumbo nucifera) root exhibits an anti-adipogenic effect in human pre-adipocytes and anti-obesity and anti-oxidant effects in rats fed a high-fat diet. Nutr Res 34:258-267. https://doi.org/ 10.1016/j.nutres.2014.01.003

52. Rayalam S, Yang J-Y, Della-Fera MA et al (2009) Anti-obesity effects of xanthohumol plus guggulsterone in 3T3-L1 adipocytes. J Med Food 12:846-853. https://doi.org/10.1089/jmf.2008.0158

53. Pal P, Kanaujiya JK, Lochab S et al (2013) Proteomic analysis of rosiglitazone and guggulsterone treated 3T3-L1 preadipocytes. Mol Cell Biochem 376:81-93. https://doi.org/10.1007/ s11010-012-1551-0

54. Keophiphath M, Achard V, Henegar C et al (2009) Macrophagesecreted factors promote a profibrotic phenotype in human preadipocytes. Mol Endocrinol 23:11-24. https://doi.org/10.1210/me. 2008-0183 